\title{
The stereoselectivity of metconazole in wheat seedling growth: implication for growth and defense balance
}

\author{
Yue Deng ${ }^{1}$, Rui Liu ${ }^{1}$, Di Wu², Li Chen ${ }^{1}$, Wenjun Zhang ${ }^{1}$, Zikang Wang ${ }^{1}$, Rujian $\mathrm{He}^{3}$, \\ Zhiqiang Zhou ${ }^{1}$, and Jinling Diao ${ }^{1}$ \\ ${ }^{1}$ China Agricultural University \\ ${ }^{2}$ Beijing Plant Protection Station \\ ${ }^{3}$ South China Normal University
}

April 28, 2020

\begin{abstract}
Triazole fungicides have a broad fungicidal activity spectrum through inhibiting the sterol biosynthesis, which damages the cell membrane function. In addition, triazoles also regulate phytohormone synthesis. Chiral pesticides have different fungicidal activities, environmental fate, and toxicities. In this study, four optical isomers and racemates of metconazole (a chiral triazole fungicide) were used to seed-coat wheat seeds $(2.5 \mathrm{~g} / 100 \mathrm{~kg}$ seed $)$ before germination. The results showed that cis1S,5R-metconazole treatment inhibited seedling emergence, which could be impeded by adding exogenous gibberellin3(GA3). Seedling morphology identified the stereoselectivity of metconazole isomers. Plants exposed to cis-1S,5R-metconazole had shorter and thicker appearance, while plants treated with trans-1S,5S-metconazole were taller and thinner, compared with the control plants. Furthermore, the effects of metconazole on plant hormones, gibberellins (GAs), and Jasmonic acid (JA) were investigated. Related enzyme activity and gene RT-qPCR results showed that trans-1S,5S-metconazole treatment upregulated the activity of related enzyme and gene expression in GAs biosynthesis. cis-1S,5R-metconazole caused down-regulation of GAs biosynthesis, and upregulation of JA synthetase activity. Moreover, all metconazole treatments increased antioxidant enzyme activity, especially trans-1S,5S-metconazole, trans-1R,5R-metconazole, and rac-metconazole. Generally, cis-1R,5S-metconazole treatment showed minimum interference of the growth of wheat seedlings, thus cis-1R,5S-metconazole may be a safer metconazole seed-coating application.
\end{abstract}

\section{Hosted file}

Manuscript.docx available at https://authorea.com/users/309517/articles/440466-the-stereoselectivityof-metconazole-in-wheat-seedling-growth-implication-for-growth-and-defense-balance 


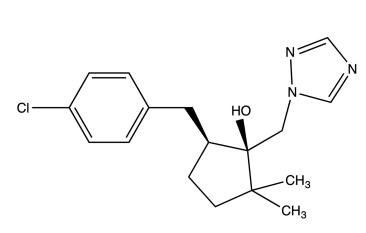

cis-1R,5S-MEZ

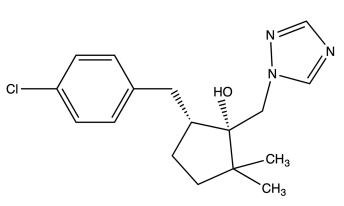

cis-1S,5R-MEZ

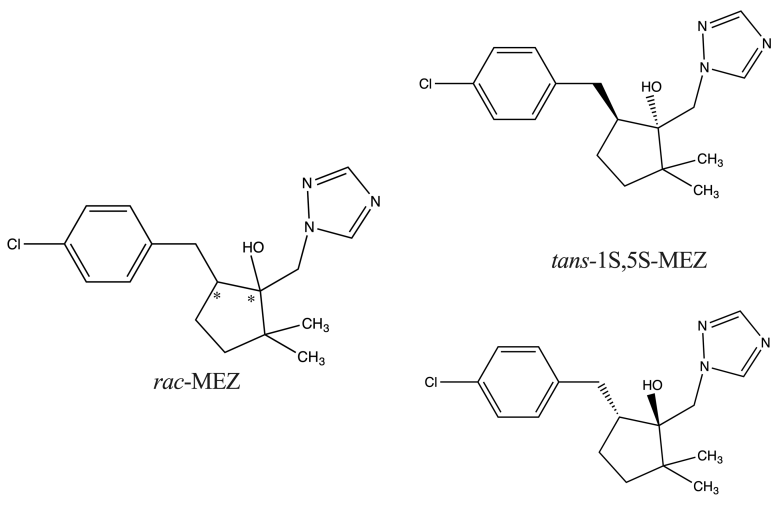

tans-1R,5R-MEZ
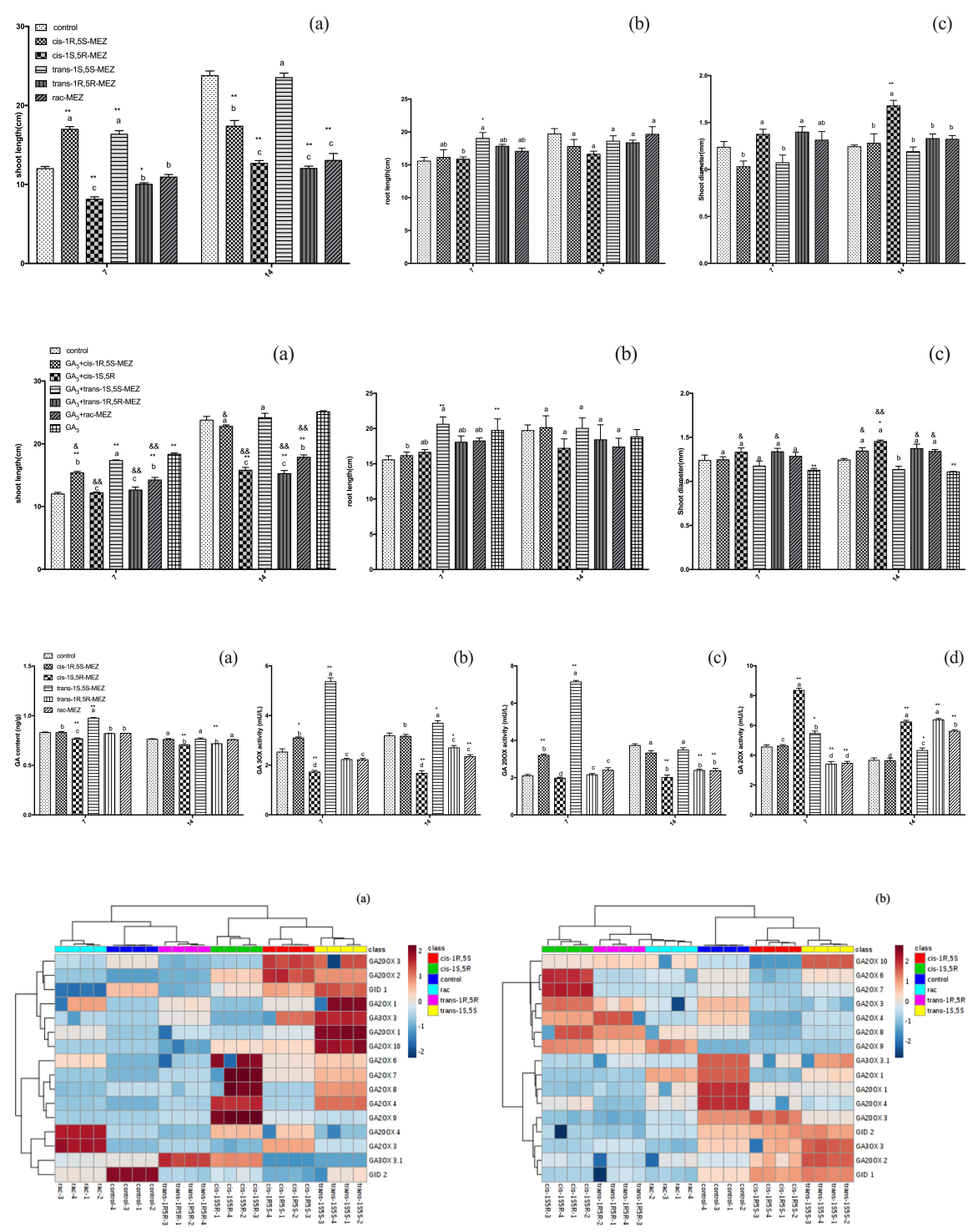


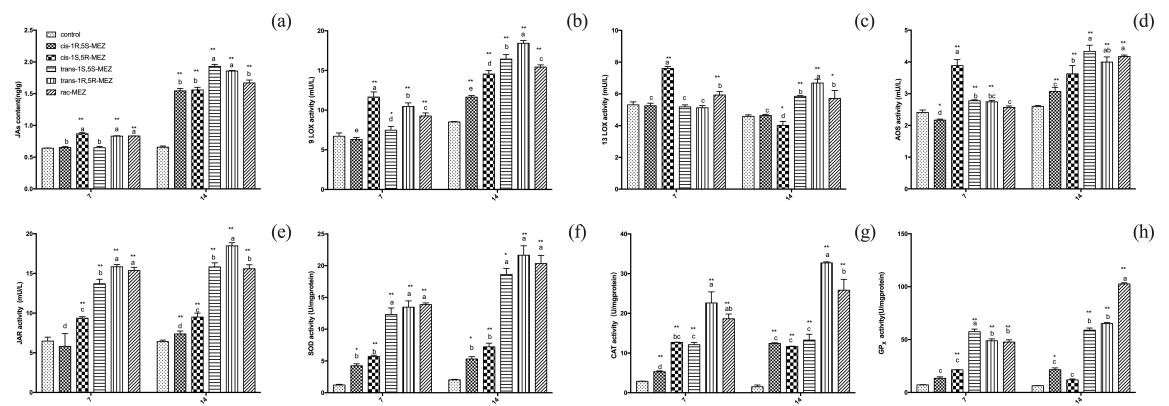

